\title{
Trade-offs in the provisioning and stability of ecosystem services in agroecosystems
}

\author{
Daniel Montoya (iD $, 1,2,3,6$ Bart Haegeman, ${ }^{1}$ Sabrina Gaba,${ }^{2}$ Claire de Mazancourt, ${ }^{1}$ Vincent Bretagnolle, 4 \\ AND Michel LOREAU ${ }^{1}$ \\ ${ }^{1}$ Centre for Biodiversity Theory and Modelling, Theoretical and Experimental Ecology Station, CNRS, 2 route du CNRS, \\ 09200 Moulis, France \\ ${ }^{2}$ Agroécologie, AgroSup Dijon, INRA, Université Bourgogne Franche-Comté, F-21000 Dijon, France \\ ${ }^{3}$ UMR Agroécologie, Centre INRA Dijon, 17 Rue Sully, F-21065 Dijon Cedex, France \\ ${ }^{4}$ Centre d'Etudes Biologiques de Chizé, UMR 7372, CNRS \& Université de La Rochelle, 79360 Villiers en Bois, France \\ ${ }^{5}$ LTSER «Zone Atelier Plaine \& Val de Sèvre», CNRS, 79360 Beauvoir sur Niort, France
}

Citation: Montoya, D., B. Haegeman, S. Gaba, C. de Mazancourt, V. Bretagnolle, and M. Loreau. 2019. Trade-offs in the provisioning and stability of ecosystem services in agroecosystems. Ecological Applications 29(2):e01853. 10.1002/eap.1853

Abstract. Changes in land use generate trade-offs in the delivery of ecosystem services in agricultural landscapes. However, we know little about how the stability of ecosystem services responds to landscape composition, and what ecological mechanisms underlie these trade-offs. Here, we develop a model to investigate the dynamics of three ecosystem services in intensively managed agroecosystems, i.e., pollination-independent crop yield, crop pollination, and biodiversity. Our model reveals trade-offs and synergies imposed by landscape composition that affect not only the magnitude but also the stability of ecosystem service delivery. Trade-offs involving crop pollination are strongly affected by the degree to which crops depend on pollination and by their relative requirement for pollinator densities. We show conditions for crop production to increase with biodiversity and decreasing crop area, reconciling farmers' profitability and biodiversity conservation. Our results further suggest that, for pollination-dependent crops, management strategies that focus on maximizing yield will often overlook its stability. Given that agriculture has become more pollination-dependent over time, it is essential to understand the mechanisms driving these trade-offs to ensure food security.

Key words: agricultural systems; biodiversity; crop production; ecosystem services; pollination; stability; trade-offs.

\section{INTRODUCTION}

Human population growth and changes in diet preferences worldwide are generating a huge demand for food (Godfray et al. 2010). To fulfil this increasing demand, agricultural intensification targets high crop yields. The merits of this approach are clear: the world annual production of cereals, grains, roots, tubers, pulses and oil crops has more than doubled, and the proportion of undernourished people in the world has decreased from $26 \%$ to $14 \%$ over the past $50 \mathrm{yr}$ (FAO 2009, 2011). But yields are no longer increasing in many major crops (Ray et al. 2012) and show saturating responses to pesticide levels (Gaba et al. 2016, Lechenet et al. 2017), which suggests that the benefits of agricultural intensification have plateaued. Furthermore, these benefits have come at a considerable cost to biodiversity. This is particularly worrying for crops whose yield depends on ecosystem functions and services, such as pollination,

Manuscript received 4 December 2017; revised 2 October 2018; accepted 19 December 2018. Corresponding Editor: David S. Schimel.

${ }^{6}$ E-mail: daniel.montoya@sete.cnrs.fr whose provision has not traditionally been part of management policies (Pywell et al. 2015, Tamburini et al. 2016).

Global agriculture largely depends on animal pollination. It is estimated that $70 \%$ of 1,330 tropical crops (Roubik 2015) and 85\% of crops in Europe (Williams 1994) benefit from animal pollination, and that pollinators can increase the production of $75 \%$ of the 115 most important crops worldwide (Aizen et al. 2009). Although the three major crops in terms of biomass are independent of animal pollination (wheat, rice, corn), the cultivated area of pollination-dependent crops is expanding faster than the area of pollinator-independent crops (Aizen and Harder 2009, Breeze et al. 2014). In contrast to the global increase in pollination-dependent agriculture, abundance and diversity of wild pollinators are declining worldwide (Goulson et al. 2015). Honey bee (and sometimes bumble bee) colonies are used to substitute wild pollinator communities, yet the pollination services of wild pollinators cannot be compensated by managed bees because (1) pollinator-dependent crop land grows more rapidly than the stock of, e.g., honey bee colonies (Aizen et al. 2009), (2) wild insects usually 
pollinate crops more efficiently than honey bees (Garibaldi et al. 2013), and (3) honey bees may depress wild pollinator densities (Lindström et al. 2016). Wild pollinators thus remain fundamental for agricultural pollination. In agricultural landscapes, the loss of seminatural habitat is considered to be the first cause of wild pollinator declines (Kennedy et al. 2013, Bretagnolle and Gaba 2015), as seminatural elements (e.g., hedgerows, lowmanaged grasslands, forest patches) provide foraging, nesting, and refuge habitats for pollinator communities (Kremen et al. 2004). This land use change therefore leads to a continuous decrease of wild pollinator communities (Garibaldi et al. 2014).

Recent studies have reported ecosystem service tradeoffs in agroecosystems (Nelson et al. 2009, Allan et al. 2015, Sutter and Albrecht 2016). For example, intensive land use favors provisioning services (e.g., crop production) at the cost of other services (e.g., pollination). More specifically, increasing crop land at the expense of seminatural habitat can largely reduce biodiversity in intensive agricultural landscapes (Allan et al. 2014), and this may drive ecosystem service trade-offs through negative effects on ecosystem services that depend on biodiversity (Cardinale et al. 2012). Thus, it may be impossible to maximize all ecosystem services simultaneously (Bateman et al. 2013). These trade-offs underpin the European Commission's Cost of Policy Inaction project (Braat and ten Brink 2008) and the land sharing vs. land sparing debate (Green et al. 2005), a framework that distinguishes between the spatial integration (land sharing) or separation (land sparing) of biodiversity conservation and crop production. A better understanding of the effects of landscape composition on crop production requires moving from the traditional single-service approach, whereby crop yield is studied individually, to a multiple-service framework (Bennett et al. 2009), where crop yield and other services, such as biodiversity and pollination, are investigated simultaneously.

There is a general consensus that decreasing levels of biodiversity can reduce the magnitude and stability of ecosystem processes (Tilman et al. 2006, Cardinale et al. 2012). In intensively managed agroecosystems, the decline in the diversity of pollinators associated with the loss of seminatural habitat can alter not only the magnitude but also the temporal stability of animal pollination-dependent crop yield, especially when biodiversity is reduced to the low levels typical of many intensive agricultural areas (Garibaldi et al. 2011a). This means that food security will not be achieved by high crop yields alone; agricultural practices should also target a stable provision of crop yield over time, as low crop yield stability can cause unpredictable negative impacts on food supply and farmer income (Schmidhuber and Tubiello 2007). Despite the importance of yield stability and the empirical evidence that the magnitude and stability of ecosystem services do not necessarily covary positively (Macfadyen et al. 2011, Gagic et al. 2012), there have been few studies on the stability of crop yield.
These studies have generally found that yield stability decreases with agricultural intensification and crop pollination dependence (Garibaldi et al. 2011a, b, 2014, Deguines et al. 2014), but the ecological mechanisms that drive these effects have received little attention.

In this study, we develop a model to predict changes in crop yield and biodiversity along a gradient of landscape composition (i.e., increasing proportions of seminatural habitat) in agricultural systems. We focus on three ecosystem services, i.e., pollinator-independent crop yield (a provisioning service), crop pollination (a regulating or supporting service), and biodiversity per se. We assess the ecosystem service of pollination by measuring crop production resulting from animal pollination. Whether or not biodiversity is an ecosystem service in itself is a matter of debate; here, we consider biodiversity as such because it is directly associated with and drives supporting (e.g., nutrient cycling, primary production) as well as cultural services (Mace et al. 2012). We distinguish between two additive ecosystem services associated with total crop yield: the yield that results from wild animal pollination (hereafter crop pollination), and the yield that is independent from animal pollination (hereafter independent crop yield). There is some debate around considering independent crop yield as an ecosystem service, as it is in part the result of human-induced mechanical and/or chemical methods of crop production (Heink et al. 2016, Barot et al. 2017). However, independent crop yield also depends on physiological rates of reproduction and growth of crops that are wind- or self-pollinated, and we thus consider it here as an ecosystem service. Besides, this separation allows us to quantitatively vary the degree of pollination dependence of crops, in contrast to studies that only make a qualitative distinction between pollination-dependent and pollinator-independent crops (Ghazoul and Koh 2010). We analyze the expected biodiversity (i.e., species richness) and the magnitude and stability of crop pollination and independent crop yield, yielding a total of five ecosystem service components. We focus on how the relative proportion of seminatural habitat and crop land in the agricultural landscape, and crop pollination dependence influence these five ecosystem service components. Specifically, we address two main questions: (1) What are the trade-offs between biodiversity and the magnitude and stability of crop pollination and independent crop yield in agricultural landscapes? and (2) How do landscape composition (the relative proportion of seminatural habitat and crop area in the agricultural landscape), and crop pollination dependence influence these trade-offs?

\section{Methods}

\section{Agroecosystem model}

We derive a model for crop biomass production in a spatially heterogeneous agricultural landscape that 
incorporates environmental and demographic stochasticity. Our model has two types of patches: crop land and seminatural habitat. Crop land is used to grow annual crops with varying degrees of dependence on wild animal pollination, whereas seminatural habitat shelters "wild" plants and pollinators. This model represents intensively managed agricultural systems, where crop land does not host significant levels of biodiversity, allowing spatial heterogeneity to be broadly defined by two patch types. Pollinators live and nest in seminatural habitats, yet they move across the landscape to forage on either crops or wild plants, or both. Crop land and seminatural habitat are therefore linked by pollinators' foraging movement. The three components of our model (pollinators, wild plants, and crop yield) are represented by the following equations:

$$
\frac{d P}{d t}=r_{\mathrm{P}}(t) P(t)\left(1-\frac{P(t)}{k_{\mathrm{P}} \omega_{\mathrm{sn}} A}\right)+\sigma_{\mathrm{P}}^{\mathrm{e}} u_{\mathrm{P}}^{\mathrm{e}}(t) P(t)+\frac{\sigma_{\mathrm{P}}^{\mathrm{d}} u_{\mathrm{P}}^{\mathrm{d}}(t)}{\sqrt{P(t)}} P(t)
$$

$$
\begin{aligned}
\frac{d W}{d t}= & r_{\mathrm{W}}(t) W(t)\left(1-\frac{W(t)}{k_{\mathrm{W}} \omega_{\mathrm{sn}} A}\right)+\sigma_{\mathrm{W}}^{\mathrm{e}} u_{\mathrm{W}}^{\mathrm{e}}(t) W(t) \\
& +\frac{\sigma_{\mathrm{W}}^{\mathrm{d}} u_{\mathrm{W}}^{\mathrm{d}}(t)}{\sqrt{W(t)}} W(t) \\
C(t)= & \left(1-\omega_{\mathrm{sn}}\right) A\left[Z_{\mathrm{C}}+\frac{\alpha_{\mathrm{C}}[P(t) / A]}{\beta_{\mathrm{C}}+[P(t) / A]}\right]\left(1+\sigma_{\mathrm{C}}^{\mathrm{e}} u_{\mathrm{C}}^{\mathrm{e}}(t)\right)
\end{aligned}
$$

where $P$ and $W$ represent the maximum yearly biomass of pollinators and wild plants, respectively. $P$ does not take managed honey bees into account as they do not depend on the availability of seminatural habitat, and they pollinate less efficiently compared to non-managed pollinators (Garibaldi et al. 2013). The model does not consider within-year dynamics. $C(t)$ is the amount of crop biomass produced in year $t$, i.e., annual crop yield. $C(t)$ is not represented by a differential equation because crops are harvested and their dynamics do not depend on the previous state. Conversely, pollinators and wild plants are not managed and their actual values depend on previous states. State variables $(P, W, C(t))$ are defined as total biomass within the agricultural landscape (Table 1 ). The variables $k_{\mathrm{P}}$ and $k_{\mathrm{W}}$ are the carrying capacities of pollinators and wild plants, respectively, per unit area; $A$ is the total landscape area (crop land and seminatural habitat); $\omega_{\mathrm{sn}}$ is the proportion of seminatural habitat within the agricultural landscape ([1 $\left.-\omega_{\mathrm{sn}}\right] \times A$ is total crop or agricultural area). The model is spatially implicit, which means that pollinators can potentially feed on all crops and wild plants present in the agricultural landscape, irrespective of the spatial configuration of the landscape. Hence, this model describes what happens in agricultural landscapes at the scale determined by the pollinator's foraging range
(200 $\mathrm{m}$ for small bee species, $25-110 \mathrm{~m}$ for bumble bees, $>200 \mathrm{~m}$ for certain bee species; Zurbuchen et al. 2010, Geib et al. 2015), which corresponds roughly to the scale of a typical arable field in Europe ( $\sim 10$ ha, including crop land and seminatural areas). However, the spatially implicit nature of the model means that it can apply to any spatial extent provided that the pollinators and, hence, the fragments of seminatural habitat that host them, are distributed in such a way that pollinators have access to the whole landscape. Therefore, the spatial extent can vary from roughly 10 ha to any larger scale provided pollinators are not aggregated in a small part of the landscape.

In the first two equations, $r_{\mathrm{P}}(t)$ and $r_{\mathrm{W}}(t)$ are the pollinators' and wild plants' per capita growth rates, and are defined as

$$
\begin{gathered}
r_{\mathrm{P}}(t)=c_{\mathrm{P}} \frac{\alpha_{\mathrm{P}}\left(\phi_{\mathrm{W}} W(t)+\phi_{\mathrm{C}} C(t)\right)}{\beta_{\mathrm{P}}+\phi_{\mathrm{W}} W(t)+\phi_{\mathrm{C}} C(t)} \\
r_{\mathrm{W}}(t)=c_{\mathrm{W}} \frac{\alpha_{\mathrm{W}}(P(t) / A)}{\beta_{\mathrm{W}}+(P(t) / A)} .
\end{gathered}
$$

Pollinators are assumed to be generalist central-place foragers that feed on both wild plants and crops (Kleijn et al. 2015). We assume that plant and pollinator uptake of resources follows a saturating, type II functional response, where $\alpha_{\mathrm{P}}$ and $\alpha_{\mathrm{W}}$ are the maximum growth rates; $\beta_{\mathrm{P}}$ and $\beta_{\mathrm{W}}$ are half-saturation constants; and $c_{\mathrm{P}}$ and $c_{\mathrm{W}}$ are the conversion rates of pollinators and wild plants, respectively, that translate the functional responses into numerical ones. For simplicity, we set conversion rates equal to unity. The pollination-dependent part of crop yield is also assumed to follow a type II functional response, where $\alpha_{C}$ is the maximum crop yield derived from pollination, $\beta_{\mathrm{C}}$ is the half-saturation constant of crops, and $\Phi_{\mathrm{W}}$ and $\Phi_{\mathrm{C}}$ are constants that convert fluxes of wild plants and crops, respectively, to pollinator biomass. We use $\Phi_{\mathrm{W}}=\Phi_{\mathrm{C}}=1$ for simplicity; to allow differences in resource quality of different crop types, we also made $\Phi_{\mathrm{C}}$ dependent on crop pollination dependence (see below paragraph). The use of saturating functional responses is widely supported and it is consistent with several biological examples (Thebault and Fontaine 2010, Holland et al. 2013, Holland 2015). A complete description of the model parameters can be found in Table 1.

Environmental stochasticity is included through the terms $\sigma^{\mathrm{e}} u^{\mathrm{e}}(t)$, where $\left(\sigma^{\mathrm{e}}\right)^{2}$ is the environmental variance of either pollinators $\left(\left(\sigma_{\mathrm{P}}^{\mathrm{e}}\right)^{2}\right)$, wild plants $\left(\left(\sigma_{\mathrm{W}}^{\mathrm{e}}\right)^{2}\right)$, or crops $\left(\left(\sigma_{\mathrm{C}}^{\mathrm{e}}\right)^{2}\right)$, and $u^{\mathrm{e}}(t)$ are random functions with zero mean and standardized variance, that can be correlated through time (a good year for plants might also be good for crops). Demographic stochasticity $\left(\sigma^{\mathrm{d}} u^{\mathrm{d}}(t)\right)$ arises from stochastic variation in individuals' births and deaths. Because crops are sown at high densities, we assume demographic stochasticity is prevented in crops, and only affects pollinators and wild plants. 
TABLE 1. Parameters and variables of the model.

\begin{tabular}{|c|c|c|}
\hline $\begin{array}{l}\text { Parameters } \\
\text { and variables }\end{array}$ & Definition & Dimensions \\
\hline \multicolumn{3}{|l|}{ Parameters } \\
\hline$\alpha_{\mathrm{P}}$ & maximum growth rate of pollinators & time $^{-1}$ \\
\hline$\alpha_{\mathrm{W}}$ & maximum growth rate of seminatural plants & time $^{-1}$ \\
\hline$\alpha_{\mathrm{C}}$ & maximum crop yield derived from pollinator interactions & mass/area \\
\hline$\beta_{P}$ & half-saturation constant of pollinators & mass \\
\hline$\beta_{\mathrm{W}}$ & half-saturation constant of "wild" plants & mass/area \\
\hline$\beta_{\mathrm{C}}$ & half-saturation constant of crop plants to pollinators & mass/area \\
\hline$k_{\mathrm{P}}$ & carrying capacity of pollinators per unit area & mass/area \\
\hline$k_{\mathrm{W}}$ & carrying capacity of seminatural plants per unit area & mass/area \\
\hline$A$ & total landscape area & area \\
\hline$\omega_{\mathrm{sn}}$ & proportion of seminatural habitat & dimensionless \\
\hline$Z_{\mathrm{C}}$ & crop yield independent of pollinators & mass/area \\
\hline$c_{\mathrm{W}}$ & conversion rate of "wild" plants (from functional to numerical response) & dimensionless \\
\hline$c_{\mathrm{P}}$ & conversion rate of pollinators (from functional to numerical response) & dimensionless \\
\hline$\Phi_{\mathrm{W}}$ & weighting factor for “wild" plants (flux to stock) & dimensionless \\
\hline$\Phi_{\mathrm{C}}$ & weighting factor for crop plants (flux to stock) & dimensionless \\
\hline$r_{\mathrm{P}}$ & intrinsic growth rate of pollinators & time $^{-1}$ \\
\hline$r_{\mathrm{W}}$ & intrinsic growth rate of "wild" plants & time $^{-1}$ \\
\hline$\sigma_{\mathrm{P}}^{\mathrm{e}}$ & environmental standard deviation of pollinators & time $^{-1 / 2}$ \\
\hline$\sigma_{\mathrm{W}}^{\mathrm{e}}$ & environmental standard deviation of "wild" plants & time $^{-1 / 2}$ \\
\hline$\sigma_{\mathrm{C}}^{\mathrm{e}}$ & environmental standard deviation of crop production & dimensionless \\
\hline$\sigma_{\mathrm{P}}^{\mathrm{d}}$ & demographic standard deviation of pollinators & mass $^{1 / 2} /$ time $^{1 / 2}$ \\
\hline$\sigma_{\mathrm{W}}^{\mathrm{P}}$ & demographic standard deviation of seminatural plants & mass $^{1 / 2} /$ time $^{1 / 2}$ \\
\hline $\begin{array}{l}u_{\mathrm{P}}^{\mathrm{v}}, u_{\mathrm{P}}^{\mathrm{d}}, u_{\mathrm{W}}^{\mathrm{e}} \\
u_{\mathrm{W}}^{\mathrm{d}}, u_{\mathrm{C}}^{\mathrm{e}}, u_{\mathrm{C}}^{\mathrm{d}}\end{array}$ & $\begin{array}{l}\text { white noise signals with zero mean and standardized variance. } \\
u^{\mathrm{e}}=\text { environmental; } u^{\mathrm{d}}=\text { demographic; } p=\text { pollinators; } \\
w=\text { "wild" plants; } c=\text { crop plants }\end{array}$ & dimensionless \\
\hline \multicolumn{3}{|l|}{ Variables } \\
\hline$C(t)$ & biomass of crop plants (crop yield) & mass \\
\hline$W(t)$ & biomass of seminatural or "wild" plants & mass \\
\hline$P(t)$ & biomass of pollinators & mass \\
\hline
\end{tabular}

Demographic stochasticity is included in the form of the first-order normal approximation commonly used in stochastic population dynamics (Lande et al. 2003), where $\left(\sigma^{\mathrm{d}}\right)^{2}$ is the demographic variance of either pollinators $\left(\left(\sigma_{\mathrm{P}}^{\mathrm{d}}\right)^{2}\right)$ or wild plants $\left(\left(\sigma_{\mathrm{W}}^{\mathrm{d}}\right)^{2}\right)$, and $u^{\mathrm{d}}(t)$ are independent random functions with zero mean and standardized variance.

Crops differ greatly in the degree to which animal pollination contributes to yield, from pollinator-independent crops, such as obligate wind- or self-pollinated species (e.g., cereals), to fully animal-pollinated species (e.g., fruit trees, oilseed rape). Within animal-pollinated species, crops differ in their level of dependence on pollination (Klein et al. 2007). In our model, $Z_{\mathrm{C}}$ represents the part of crop yield that is independent of animal pollination and $\alpha_{\mathrm{C}}$ is the crop yield derived from pollination, therefore we can estimate crop pollination dependence $(\%)$ as $\alpha_{C} /\left(\alpha_{C}+Z_{C}\right)$. If $Z_{C}=0\left(\alpha_{C}>0\right)$, crop yield depends entirely on animal pollination; conversely, animal pollination-independent crops are defined by $\alpha_{C}=0$ $\left(Z_{\mathrm{C}}>0\right)$. Most fruit and seed crops lie between these two extremes $\left(Z_{\mathrm{C}}>0, \alpha_{\mathrm{C}}>0\right)$. We assume there is no interaction between $\alpha_{\mathrm{C}}$ and $Z_{\mathrm{C}}$ (Bartomeus et al. 2015, Gils et al. 2016).

\section{Mean and stability of ecosystem services}

We use our model to quantify biodiversity and both the mean and the stability of independent crop yield and crop pollination, which make five ecosystem service components, in intensively managed agricultural landscapes with varying proportions of seminatural habitat. We assume that, at the end of each cropping season, the amount of animal pollinators, wild plants and crops reach roughly constant values in the absence of environmental and demographic stochasticity at the landscape scale, despite local year-to-year changes in those variables. This year-to-year equilibrium assumption is a reasonable first approximation to a more complex and dynamical system. We use the species-area relationship (SAR) to estimate changes in pollinator biodiversity as a function of seminatural area. We decided to use SAR for estimating biodiversity instead of wild plant biomass or pollinator biomass, because species-biomass relationships are more variable at local/landscape scales such as the one considered here, and negative relationships have been reported (e.g., diversity-productivity; Cardinale et al. 2012). Moreover, when biodiversity is considered a cultural service, it is usually estimated as 
the number of species. Despite the fact that SAR is usually stronger at spatial scales larger than that of arable fields, where we might observe more variation around the average biodiversity values, it captures the expected mean biodiversity at the scale of an arable field in Europe. We estimated SAR using the conventional power law function $\left(S=c\left[\omega_{\mathrm{sn}} A\right]^{z}\right.$, where $S$ is the number of species and $c$ is a constant of proportionality). Theoretical models and field data from a wide range of plant and animal taxa show that the slope, $z$, of the logarithm of species richness against the logarithm of area is roughly constant, with $z \approx 0.25$ (Crawley and Harral 2001). Given that the equilibrium plant and pollinator biomasses are proportional to the area of seminatural area (Appendix S6: Fig. S1), considering either species richness or biomass would yield the same qualitative results $\left(R^{2}=0.90\right.$; at the scale of this study, $z$ can be higher [0.4 or 0.5]; Crawley and Harral 2001), yielding an even stronger correlation between the number of species and biomass). We assume that crops are harvested yearly; hence, average crop yield represents the temporal mean of the yearly averaged crop yield across the agricultural landscape. To account for the stability of independent crop yield and crop pollination, we use the inverse of temporal variability, i.e., invariability. Temporal variability is measured as the square of the temporal coefficient of variation $\left(\mathrm{CV}^{2}\right)$ of total biomass, i.e., the ratio of the variance to the square of the mean, and is calculated in the stationary regime around the equilibrium. We use $1 / \mathrm{CV}^{2}$ as a metric of stability (i.e., invariability) of independent crop yield and crop pollination. This measure of ecosystem stability has been used in recent empirical and experimental studies (Tilman et al. 2006, Loreau and de Mazancourt 2013).

We derived analytical expressions for the equilibrium values of pollinator biomass, wild plant biomass, and crop yield (Appendix S1: Eqs. S6-S8). We used these expressions to simplify the model by assuming that the deviations from equilibrium are small, i.e., we linearized the nonlinear dynamical system. This linear approximation allowed us to quantify how the plant-pollinator system responds to small stochastic perturbations, including environmental and demographic stochasticity. In particular, we derived analytical expressions for the variability of pollinator biomass, wild plant biomass and crop yield (Appendix S1: Eqs. S18-S23). We verified the accuracy of these analytical results by numerically simulating the stochastic model equations. A summary of the equations for the five ecosystem service components can be found in Appendix S2 (Eqs. S5-S9). Our analytical expressions allowed us to exhaustively study the dependence of the mean and stability of ecosystem services on all model parameters. The results reported in the figures are based on these analytical expressions.

Whenever possible, we estimated parameter values with empirical information. In other cases, we informed parameters with commonly assigned values found in the literature (McCann et al. 2005, Thompson et al. 2006, Leroux and Loreau 2008, Holland and DeAngelis 2010, Thebault and Fontaine 2010, Morales 2011, Holland et al. 2013, Encinas-Viso et al. 2014, Gounand et al. 2014). For example, to determine the carrying capacity of pollinators $\left(k_{\mathrm{P}}\right)$, we used empirical data on average numbers of individuals and body mass of wild pollinators (Bommarco et al. 2012, Rollin et al. 2013, Holzschuh et al. 2016). For wild plants, we used empirical observations to inform their carrying capacities $\left(k_{\mathrm{W}}\right.$; Craven et al. 2016). Also, there is information on independent crop yield that was used to determine $Z_{C}$ (e.g., data available online). ${ }^{7}$ We allowed variation in $\alpha_{\mathrm{C}}$ and $\beta_{\mathrm{C}}$ in order to investigate changes in the five ecosystem services components across the amount of seminatural habitat $\left(\omega_{\mathrm{sn}}\right)$, the degree of crop pollination dependence $\left(Z_{C} / \alpha_{C}\right)$, and the crop relative requirement for pollinator densities $\left(\beta_{\mathrm{C}} / k_{\mathrm{P}}\right)$. A sensitivity analysis was performed for parameter whose values could not be determined precisely or for which there was variation in their values assigned in the literature, e.g., $\alpha_{\mathrm{C}}, \alpha_{\mathrm{P}}, Z_{\mathrm{C}}, \beta_{\mathrm{C}}, \beta_{\mathrm{P}}, k_{\mathrm{P}}$ (Appendix S3). The choice of these parameters for the sensitivity analyses is also justified because they are most relevant for the estimation of equilibrium biomasses. Sensitivity analysis shows that variations in these parameter values did not change the results qualitatively. Analyses were performed in $\mathrm{R}$ software ( $\mathrm{R}$ version 3.2.4; R Core Team 2016).

\section{Results}

\section{Overall effects of landscape composition on ecosystem service components}

Increases in the relative proportion of crop land has contrasting effects on the various ecosystem services. As expected, biodiversity increases with the proportion of seminatural habitat, as the latter provides area for many taxonomic groups, such as wild plants and pollinators (Fig. 1a). Changes in the biomasses of wild plants and pollinators with seminatural habitat are positively correlated with changes in biodiversity $\left(R^{2}=0.90\right.$; Appendix S6: Fig. S1). The responses of the pollinationindependent and pollination-dependent (i.e., crop pollination) components of crop yield differ strongly. Independent crop yield decreases linearly with the amount of seminatural habitat because crop land decreases and it does not depend on pollinators (Fig. 1c). In contrast, the relationship between crop pollination and the proportion of seminatural habitat is hump-shaped (Fig. 1b), as a result of the contrasting effects of seminatural habitat on pollinators and crop land. That is, a larger amount of seminatural habitat increases wild pollinator biomass (Appendix S6: Fig. S1b) but reduces crop land, which results in a hump-shaped relationship that is robust to changes in parameter values (Appendix S3).

\footnotetext{
${ }^{7}$ http://data.worldbank.org/
} 

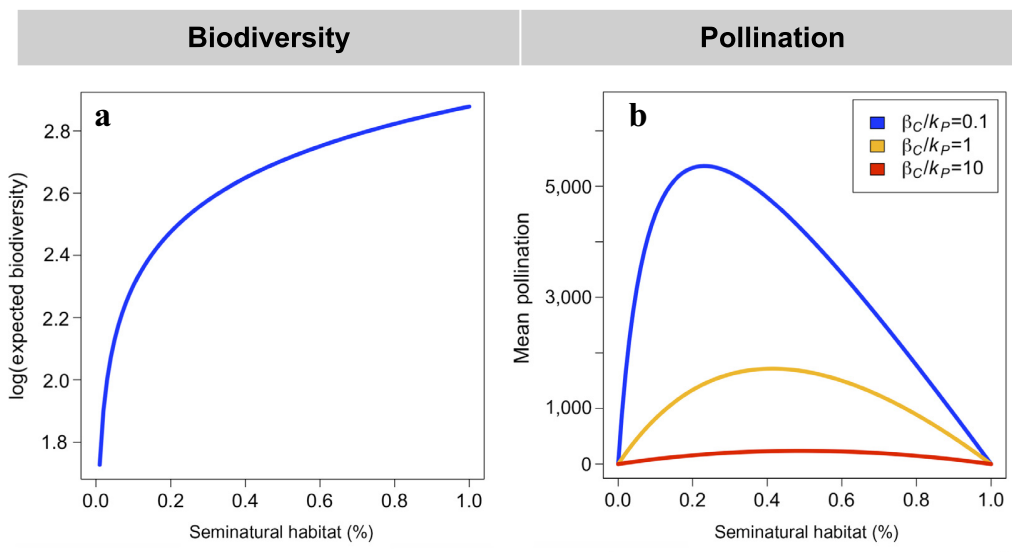

Independent crop yield
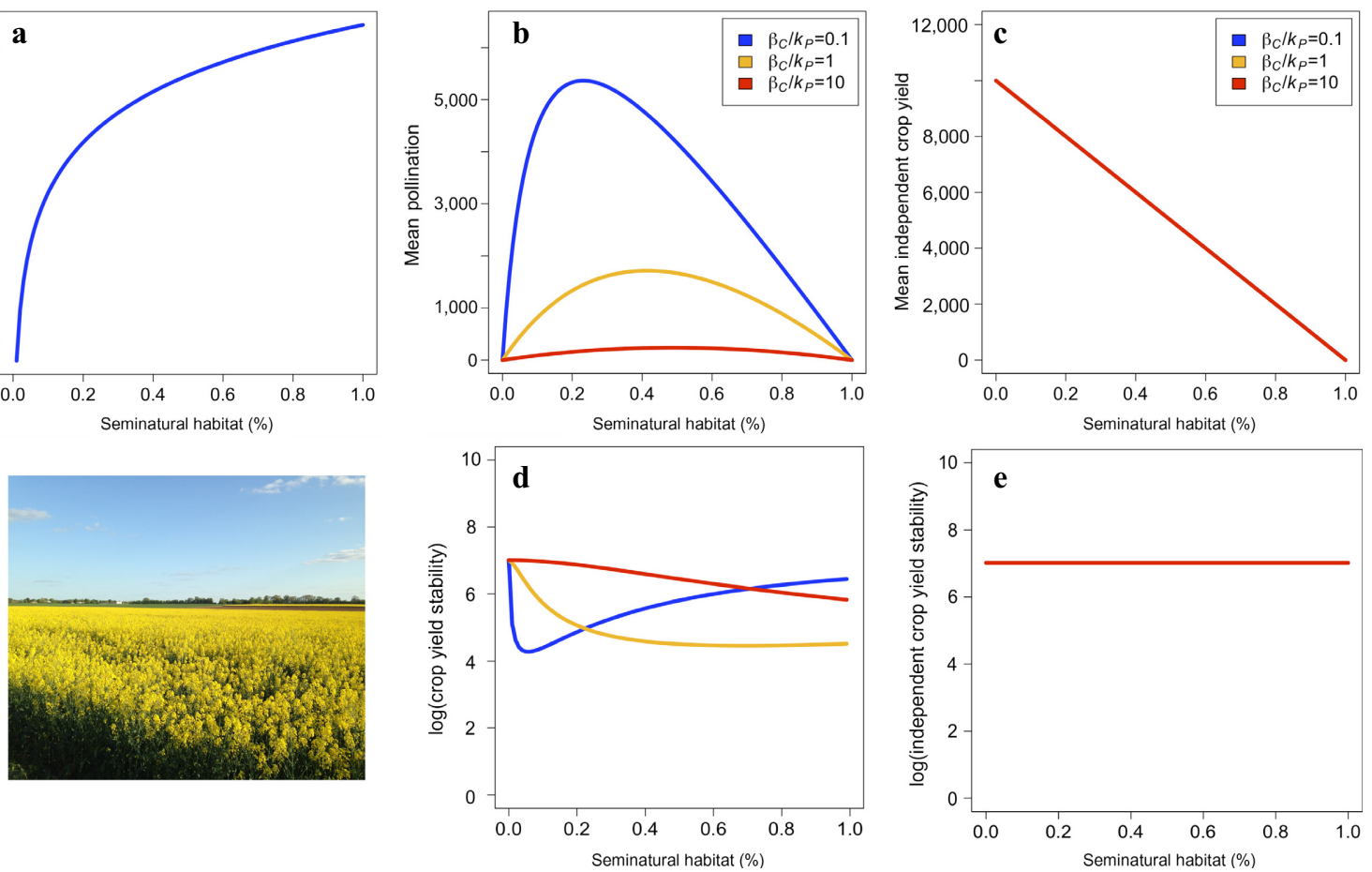

FIG. 1. Mean and stability of five ecosystem service components in agroecosystems. This figure shows (a) the expected biodiversity, the (c) temporal mean and (e) stability $\left(\log \left[1 / \mathrm{CV}^{2}\right]\right)$ of independent crop yield, and the (b) temporal mean and (d) stability $\left(\log \left[1 / \mathrm{CV}^{2}\right]\right)$ of crop pollination as functions of the proportion of seminatural habitat for different crop relative requirement for pollinators $\left(\beta_{\mathrm{C}} / k_{\mathrm{P}}\right)$. Because $\beta_{\mathrm{C}} / k_{\mathrm{P}}$ does not affect biodiversity and the mean/stability of independent crop yield, a single line is shown. Picture of an intensive agricultural landscape in the LSTER Zone Atelier Plaine \& Val de Sèvre, France (Photo credit: Sabrina Gaba). Parameter values: $\alpha_{\mathrm{P}}=0.9, \quad \beta_{\mathrm{P}}=0.6, A=10, Z_{\mathrm{C}}=1,000, \quad \alpha_{\mathrm{C}}=1,000, k_{\mathrm{W}}=5,000, \quad k_{\mathrm{P}}=0.1, \quad \sigma_{\mathrm{P}}^{\mathrm{e}}=0.8, \quad \sigma_{\mathrm{P}}^{\mathrm{d}}=0.1$, $\sigma_{\mathrm{C}}^{\mathrm{e}}=0.03, \alpha_{\mathrm{C}}=1,000$, Pollination dependence $=50 \%$; species-area relationship $\left.\left[S=\mathrm{c}\left(\omega_{\mathrm{sn}} A\right)^{z}\right]: \mathrm{c}=10, z=0.25\right)$. Parameters are defined in Table 1.

Total crop yield, i.e., pollination-independent plus pollination-dependent crop yields, displays a similar humpshaped relationship, especially when crop pollination dependence is moderate to high (Appendix S6: Fig. S2). Interestingly, when measured per unit of crop land, crop yield increases with the proportion of seminatural habitat, because of the beneficial effect of pollination (Appendix S6: Fig. S3).

The stability of independent crop yield does not change with seminatural habitat (Fig. 1e) because it does not rely on animal pollination. On the other hand, pollination-dependent yield does depend on animal pollinators, thus crop pollination stability strongly depends on the amount of seminatural habitat (Fig. 1d). Crop stability shows similar trends when measured at landscape scale or per unit of agricultural area.

\section{Role of pollination dependence and crop relative requirement for pollinators}

The dependence of crop yield mean and stability on the proportion of seminatural habitat is controlled by two effective parameter combinations, $Z_{\mathrm{C}} / \alpha_{\mathrm{C}}$ and $\beta_{\mathrm{C}} / k_{\mathrm{P}}$
(Appendix $\mathrm{S} 1$ ). $Z_{\mathrm{C}}$ is the pollinator-independent component of crop yield and $\alpha_{C}$ is the maximum crop yield derived from pollinator interactions, so $Z_{C} / \alpha_{C}$ is inversely related to crop pollination dependence:

$$
\text { Pollination dependence }=\frac{1}{1+Z_{\mathrm{C}} / \alpha_{\mathrm{C}}} .
$$

$\beta_{\mathrm{C}} / k_{\mathrm{P}}$ is the ratio of crop half-saturation constant relative to pollinators' carrying capacity, and it quantifies the pollinator requirement of crops relative to the availability of pollinators, i.e., crop relative requirement for pollinators. For small values of $\beta_{\mathrm{C}} / k_{\mathrm{P}}(<1)$, crop yield saturates at lower pollinator biomass than their carrying capacity, but for large values of $\beta_{\mathrm{C}} / k_{\mathrm{P}}(>1)$, crop yield saturates at pollinator biomasses much higher than their carrying capacities.

Biodiversity is negatively correlated with mean independent crop yield and is unrelated to its stability (Fig. 1a, c). For increasing levels of pollination dependence, both the mean and stability of total crop yield are increasingly affected by pollination and hence by the amount of seminatural habitat (Fig. 2). The position of 

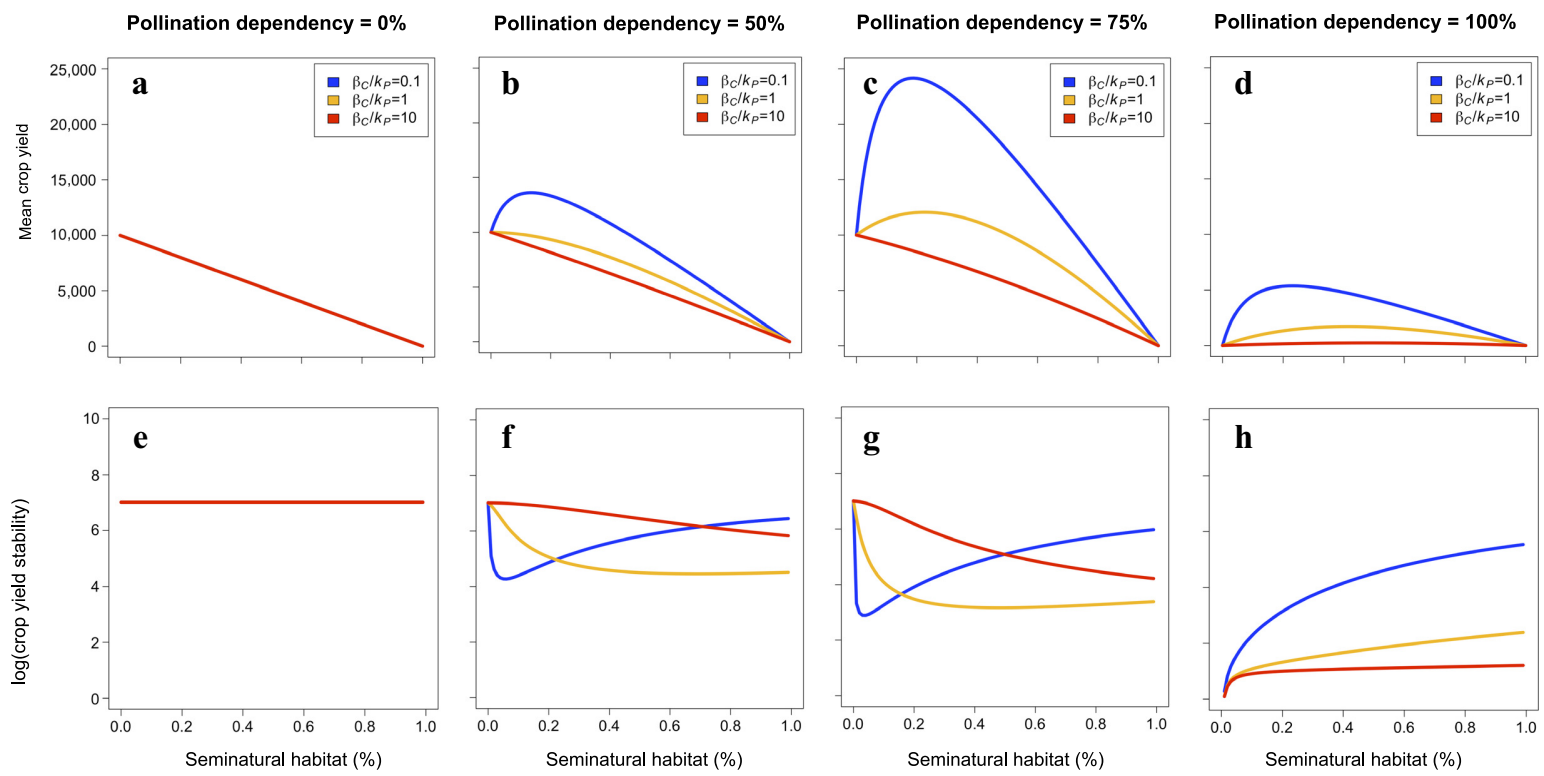

FIG. 2. Mean and stability of total crop yield. Temporal mean and stability $\left(\log \left[1 / \mathrm{CV}^{2}\right]\right)$ of total crop yield as functions of pollination dependence and crop relative requirement for pollinators. In panels a and e, the three curves overlap (parameter values: $\left.\alpha_{\mathrm{P}}=0.9, \beta_{\mathrm{P}}=0.6, A=10, k_{\mathrm{W}}=5,000, \sigma_{\mathrm{P}}^{\mathrm{e}}=0.8, \sigma_{\mathrm{P}}^{\mathrm{d}}=0.1, \sigma_{\mathrm{C}}^{\mathrm{e}}=0.03, \alpha_{\mathrm{C}}=1,000\right)$. Because $Z_{\mathrm{C}}=1,000, \alpha_{\mathrm{C}}$ is allowed to increase with higher pollination dependences; this is why mean crop yield increases with pollination dependence of crops. In panels a and e, $\alpha_{\mathrm{C}}=0$ and $Z_{\mathrm{C}}=1,000$. In panels $\mathrm{d}$ and $\mathrm{h}, \alpha_{\mathrm{C}}=1000$ and $Z_{\mathrm{C}}=0$ ). In panels $\mathrm{b}, \mathrm{c}, \mathrm{f}$, and $\mathrm{g}, Z_{\mathrm{C}}=1,000$ and $\alpha_{\mathrm{C}}$ is allowed to vary to reflect different levels of crop pollination dependence.

the maximum yield along the seminatural gradient changes with crop pollination dependence and crop relative requirement for pollinators. On one hand, for higher levels of pollination dependence crops require more pollinators and thus maximum crop yield is achieved at larger proportions of seminatural habitat. On the other hand, high crop relative requirement for pollinators (high $\beta_{\mathrm{C}} / k_{\mathrm{P}}$ ) has the dual effect of reducing mean yield and shifting maximum yield to larger amounts of seminatural habitat. In general, high crop relative requirement for pollinators is less responsive to the amount of seminatural habitat, because pollinator densities that will be achieved in the agricultural landscape are unlikely to fulfill crop relative requirement for pollinators (Appendix S4). Mean crop yield per unit of agricultural area increases with the proportion of seminatural habitat (Appendix S6: Fig. S3), although it starts to show some saturation when crop relative requirement for pollinators is low. Finally, we explored the effect of resource quality of different crop types and showed that these results are robust to differences in resource quality of different crop types (e.g., $\Phi_{C} \sim \alpha_{C}$ l $\left(\alpha_{\mathrm{C}}+Z_{\mathrm{C}}\right)$; Appendix S4).

In pollination-dependent crops, the stability of pollination also changes with the fraction of seminatural habitat: it first decreases (due to the demographic and environmental stochasticity of pollinators), and then increases after a minimum fraction of seminatural habitat has been reached (due to a drop in the response of crops to pollinator stochasticity), although this response is heavily conditioned by the crop relative requirement for pollinators (Fig. 2e-h; Appendix S4). Whereas a higher pollination dependence of crops reduces pollination stability and broadens the range of stability values, crops with a lower pollination dependence are little affected by pollinator stochasticity, and yield stability is mostly determined by the environmental stochasticity of crops. Within each level of crop pollination dependence (Fig. 2) the response of yield stability to seminatural habitat is conditioned by crop relative requirement for pollinators: a low crop relative requirement for pollinators (low $\beta_{\mathrm{C}} / k_{\mathrm{P}}$ ) shifts the stability valley to lower fractions of seminatural habitat, and stability increases faster. Increasing $\beta_{\mathrm{C}} / k_{\mathrm{P}}$ expands the region of low stability, and stability requires larger areas of seminatural habitat to increase. When crop relative requirement for pollinators is very high (high $\beta_{\mathrm{C}} / k_{\mathrm{P}}$ ), crop yield stability decreases monotonically along the full gradient of seminatural habitat. A detailed analysis of the effects of the various sources of stochasticity is provided in Appendix S5.

In sum, the contrasting effects of increasing crop land on the various ecosystem services reveal trade-offs (negatively correlated responses) and synergies (positively correlated responses) in the response of biodiversity and the mean and stability of independent crop yield and crop pollination (Fig. 3). The exact shape of the ecosystem service trade-offs across the gradient of seminatural habitat is controlled by the degree to which crops depend on pollination $\left(Z_{C} / \alpha_{C}\right)$ and by their relative requirement for pollinator densities $\left(\beta_{\mathrm{C}} / k_{\mathrm{P}}\right)$. Variations in parameter values did not change results qualitatively. 


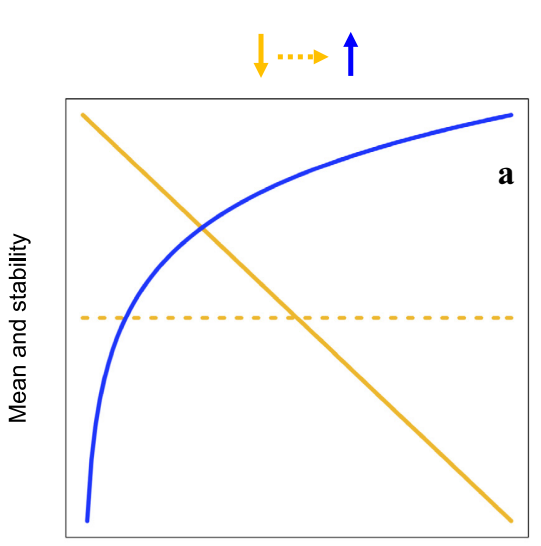

$\%$ Semi-natural habitat

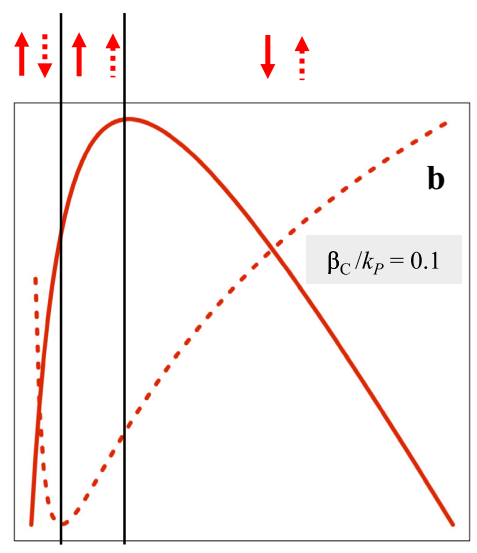

$\%$ Semi-natural habitat

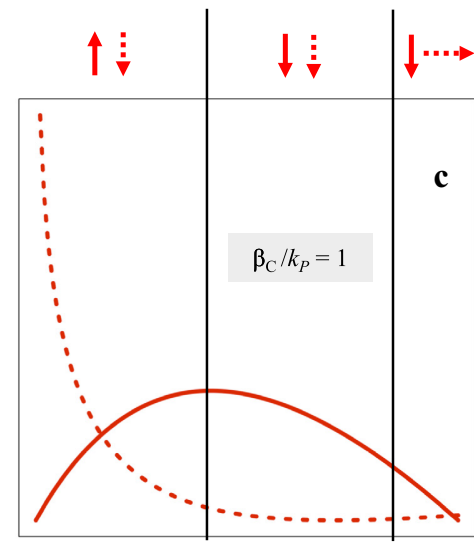

$\%$ Semi-natural habitat

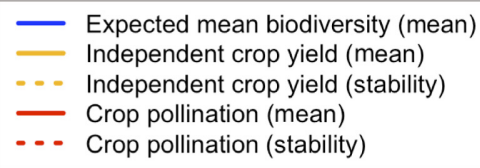

FIG. 3. A variety of trade-offs and synergies between ecosystem service components in agroecosystems. This graph shows the expected biodiversity and the temporal mean and stability $\left(\log \left[1 / \mathrm{CV}^{2}\right]\right)$ of (a) independent crop yield and (b, c) crop pollination as functions of the proportion of seminatural habitat. The responses of the mean and stability of the three ecosystem services to land use intensification produce different patterns across the gradient of seminatural habitat, from trade-offs (negatively correlated responses, opposite arrows) to synergies (positively correlated responses, similar arrows). Independent crop yield and biodiversity (panel a) are not affected by crop relative requirement for pollinators $\left(\beta_{\mathrm{C}} / k_{\mathrm{P}}\right)$. Conversely, crop pollination mean and its stability, and therefore ecosystem service synergies and trade-offs, are controlled by crop relative requirement for pollinators: (b) $\beta_{\mathrm{C}} / k_{\mathrm{P}}=0.1$, (c) $\beta_{\mathrm{C}} / k_{\mathrm{P}}=1$ (see Results and Appendix S1). The $y$-axes are unitless to make comparison between curves clearer. Parameter values: $\alpha_{\mathrm{P}}=0.9, \beta_{\mathrm{P}}=0.6, A=10, Z_{\mathrm{C}}=1,000, \alpha_{\mathrm{C}}=1,000, k_{\mathrm{W}}=5,000, k_{\mathrm{P}}=0.1, \sigma_{\mathrm{P}}^{\mathrm{e}}=0.8, \sigma_{\mathrm{P}}^{\mathrm{d}}=0.1, \sigma_{\mathrm{C}}^{\mathrm{e}}=0.03, \alpha_{\mathrm{C}}=1,000$, pollination dependence $=50 \%$; species-area relationship $\left[S=\mathrm{c}\left(\omega_{\mathrm{sn}} A\right)^{z}\right]: \mathrm{c}=10, z=0.2$.

\section{DisCUSSION}

In intensively managed agricultural systems, increases in the amount of crop land relative to that of seminatural habitat have major consequences for the provision of ecosystem services. Our model suggests that (1) changes in landscape composition generate a variety of synergies and trade-offs between biodiversity conservation, crop pollination, and independent crop yield, (2) these tradeoffs affect not only the magnitude but also the stability of these ecosystem services, and (3) the trade-offs involving crop pollination are strongly affected by the degree to which crops depend on pollination and by their relative requirement for pollinator biomass.

The loss of seminatural habitat has contrasting effects on the three ecosystem services considered: biodiversity decreases, independent crop production increases, while pollination-dependent crop production is maximized at an intermediate proportion of seminatural habitat. These results provide rigorous theoretical foundations for previously hypothesized functional relationships between the magnitude of ecosystem services and landscape composition (Braat and ten Brink 2008). The results further suggest that the exact shape of the humpshaped relationship between provisioning services and seminatural habitat is determined by the pollination dependence and the relative requirement of crops for pollinator densities (Figs. 2, 3). Greater values of these two factors increase the effect of pollinator biomass on total crop yield, and thus the maximum yield is achieved at higher fractions of seminatural habitat.

Importantly, our results suggest that landscape composition also imposes trade-offs on the stability of crop yield. These trade-offs are driven by mechanisms associated with the stochasticity of pollinators and the response of crops to that stochasticity. On the one hand, the stability of crop pollination decreases with the amount of seminatural habitat when the latter is small because pollinator stochasticity increases. For larger proportions of seminatural habitat, however, the response of crop yield to pollinator stochasticity drops, with varying effects on pollination stability. The decay in crop response to pollinator stochasticity is caused by the saturation of pollination-dependent crop yield to pollinator biomass (Appendix S4). Crop relative requirement for pollinators controls how fast saturation sets in and, consequently, how fast the response of crops to pollinator stochasticity drops down.

Taken together, the responses of the mean and stability of ecosystem services to landscape composition produce different patterns across the gradient of seminatural habitat, from trade-offs (negatively 
correlated responses) to synergies (positively correlated responses; Fig. 3). At the landscape scale, we found a trade-off between independent mean crop yield and biodiversity, and between crop pollination and independent crop yield when seminatural habitat is low. Conversely, at low fractions of seminatural habitat, we observed a synergy between crop pollination and biodiversity. Such synergy between crop production and biodiversity also became apparent when considering crop production per unit of agricultural area, revealing the possibility to reconcile farmers' profitability (at field scale) and biodiversity conservation (at landscape scale). Trade-offs and synergies can also occur within ecosystem services, e.g., crop pollination mean and its stability covary negatively except at low-to-intermediate amounts of seminatural habitat. These patterns give moderate support to the intermediate landscape-complexity hypothesis (Tscharntke et al. 2012), which states that the effectiveness of agro-environmental management strategies is higher in simple $(1-20 \%$ non-crop area) than in either cleared $(<1 \%$ non-crop area) or complex ( $>20 \%$ non-crop area) landscapes. For moderate to high levels of crop pollination dependence and high crop relative requirement for pollinators, increases in the amount of seminatural habitat benefit biodiversity and crop pollination both in terms of average provision and stability in simple landscapes. Despite simple agricultural landscapes are often areas where cultivated crops have a low degree pollination dependency (except from species like oilseed rape and sunflower), these benefits are also larger in simple landscapes when crop yield per unit of agricultural land is considered. Surprisingly though, with a few exceptions (Duflot et al. 2015), most intensively managed agricultural landscapes show very low proportions of seminatural habitat $(<5 \%$; Öckinger and Smith 2007, Henckel et al. 2015). Additionally, increasing the amount of seminatural habitat benefits other services such as pest control (Sutter and Albrecht 2016). In sum, consistent with empirical observations (Pywell et al. 2015, Tamburini et al. 2016), the existing trade-offs and synergies suggest that moderate increases in the amount of seminatural habitat in simple agricultural landscapes $(1-20 \%$ noncrop area) allow ecosystem services essential for crop production to be maintained, which, in turn, increases the magnitude and stability of crop yield.

Our findings are also consistent with recent studies suggesting that the interaction between agricultural intensification and the level of pollination dependence of crops determines the stability of crop production at large spatial scales. For instance, using an intensification index that includes the amount of seminatural habitat in agroecosystems, a recent study found that the stability of the yield of the 54 major crops in France decreases in more intensive agriculture, and that this reduction is more pronounced for higher crop pollination dependence (Deguines et al. 2014). Similarly, long-term data from FAO suggest that a greater pollination dependence of crops leads to lower and less stable crop yields
(Garibaldi et al. 2011a). By considering various interrelated ecosystem services simultaneously, our results add a mechanistic understanding of these ecosystem service trade-offs in intensively managed agroecosystems.

The trade-offs in ecosystem service provision revealed by our model have two major implications for the management of intensive agricultural systems. First, the effects of biodiversity loss on crop production that result from agricultural intensification depend on the level of pollination dependence of crops. Whereas in pollinatorindependent agriculture (e.g., staple food crops such as wheat, rice, corn, soybean, sorghum, bananas) reductions in biodiversity and crop pollination have no effect on provisioning services (crop production), for pollination-dependent agriculture (e.g., most fruit crops such as Prunus spp., Malus spp., watermelon, Cucurbita spp.) crop production relies on biodiversity (e.g., wild plants provide foraging, nesting, and refuge for pollinators), and the trade-off between biodiversity conservation and crop production is mediated by biodiversity loss. Such reduction in biodiversity reduces the delivery of regulating services, and this has a direct negative effect not only on mean yield but also on its stability. Second, our results suggest that simultaneously maximizing crop yield mean and stability is often impossible for pollination-dependent crops, and therefore, management strategies that focus on maximizing mean yield will overlook its stability. Specifically, enhancing crop yield by increasing crop land would be counterproductive for pollination-dependent crops, at least below a threshold of seminatural habitat. There is, however, a notable exception to this: maximization of crop yield mean (both at the landscape scale and per unit of agricultural area) and crop yield stability can be achieved at $20-40 \%$ of seminatural habitat when crops show intermediate to high degrees of animal pollination dependence and crop relative requirement for pollinators is low.

The yield mean and stability of crops with greater pollinator dependence has continuously decreased from 1961 to 2008 (Garibaldi et al. 2011a). This suggests that the relative requirement for pollinators of many world crops is high, as pesticide use has diminished the carrying capacity of pollinators in seminatural habitat during the same period of time (Goulson et al. 2015). To compensate for low crop yields, agricultural policies have promoted land cultivation of pollination-dependent crops and the use of managed honey bee colonies, which are not affected by seminatural habitat. However, these measures reduce the amount of seminatural area and honey bees cannot compensate for the pollination services of non-managed, wild pollinators (Aizen et al. 2009, Garibaldi et al. 2013). Our model suggests that an alternative to agricultural intensification consists in diminishing crop relative requirement for pollinators with practices that increase the carrying capacity of pollinators in seminatural habitat, such as higher farmland heterogeneity and floral assemblages, increasing nesting opportunities, and reductions in the use of synthetic 
pesticides (Garibaldi et al. 2014). These measures may not only increase mean crop yield at the landscape scale or per unit of agricultural area, but also its stability.

Our model has several limitations. For example, our model and the observed trade-offs between biodiversity and crop yield refer to intensively managed agricultural systems, where crop land does not host important biodiversity levels; however, these trade-offs are not necessarily similar in non-intensive agricultural systems where biodiversity can moderately thrive within crop land (Clough et al. 2011). Second, the species-area relationship is stronger at spatial scales larger than that of arable fields, where we might expect more variation around the expected biodiversity values; yet, our simple model captures the expected mean biodiversity at the scale of an arable field in Europe. Besides, the observation that biodiversity loss has either none (stability) or positive (mean) effects on independent crop yield is based on the species-area relationship; these effects are likely to differ if taxonomic groups responsible for other ecosystem services, i.e., pest control, are more specifically included. Our approach is relevant for other ecosystem services affected by cross-habitat spill-over between crop land and seminatural habitat such as pest control (Macfadyen and Muller 2013, Sutter and Albrecht 2016), and our model could be expanded to account for such services, as their dynamics likely differs from those of pollinators. Also, our model is spatially implicit, and does not consider the effects of the spatial configuration of seminatural habitat (Garibaldi et al. 2011b, Mitchell et al. 2015); future studies should consider space explicitly, as the spatial distribution of seminatural habitat within the agricultural landscape determines the ecosystem service flows between seminatural habitat and crop land, including pollination (Brosi et al. 2008, Keitt 2009, Serna-Chavez et al. 2014). Finally, we find that the amount of seminatural habitat has no effect on the stability of independent crop yield. This may change, however, if environmental stochasticity of crops increases with decreasing amounts of seminatural habitat, as suggested by studies linking seminatural habitat to climate regulation, natural hazard regulation and water flow regulation services (Harrison et al. 2010). Despite these limitations, our model is a very useful first step as it successfully reproduces the results of recent empirical studies on the stability of pollinationdependent crop yield and it provides a mechanistic understanding of the trade-offs that are relevant in intensively managed agroecosystems.

\section{Conclusions}

Although historically the demand for increased crop production has been satisfied by agricultural practices that promote land conversion to crop land and improvements in crop yield (e.g., fertilizers, pesticides, selection of high-yield crop strains), the benefits of this approach have started to be challenged. The present study sheds new light on this debate. Our model suggests that landscape composition imposes trade-offs on several ecosystem services in intensively managed agroecosystems. These trade-offs not only affect the mean production of crops, but also their temporal stability, in such a way that high and stable crop yields are not necessarily associated. This suggests that an approach that simultaneously considers the magnitude and stability of multiple ecosystem services is needed to understand and better manage agricultural systems. In order to develop a more efficient agriculture and ensure food security, it is essential to understand the mechanisms driving the trade-offs between multiple ecosystem services.

\section{ACKNOWLEDGMENTS}

D. Montoya was funded by the EU and INRA in the framework of the Marie-Curie FP7 COFUND People Program, through the award of an AgreenSkills/AgreenSkills+ fellowship. This work was supported by the TULIP Laboratory of Excellence (ANR-10-LABX-41), by the ANR AGROBIOSE (ANR13-AGRO-0001), ERANET ECODEAL, and by the BIOSTASES Advanced Grant, funded by the European Research Council under the European Union's Horizon 2020 research and innovation program (grant agreement No 666971). The authors thank the Centre for Biodiversity Theory and Modelling (CBTM) laboratory members for helpful discussion.

\section{Literature Cited}

Aizen, M. A., L. A. Garibaldi, S. A. Cunningham, and A. M. Klein. 2009. How much does agriculture depend on pollinators? Lessons from long-term trends in crop production. Annals of Botany 103:1579-1588.

Aizen, M. A., and L. D. Harder. 2009. The global stock of domesticated honey bees is growing slower than agricultural demand for pollination. Current Biology 19:915-918.

Allan, E., et al. 2014. Interannual variation in land-use intensity enhances grassland multidiversity. Proceeding of the National Academy of Sciences USA 111:308-313.

Allan, E., et al. 2015. Land-use intensification alters ecosystem multifunctionality via loss of biodiversity and changes to functional composition. Ecology Letters 18:834-843.

Barot, S., L. Yé, L. Abbadie, L. Blouin, and N. Frascaria. 2017. Ecosystem services must tackle anthropized ecosystems and ecological engineering. Ecological Engineering 99:486-495.

Bartomeus, I., V. Gagic, and R. Bommarco. 2015. Pollinators, pests and soil properties interactively shape oilseed rape yield. Basic and Applied Ecology 16:737-745.

Bateman, I. J., et al. 2013. Bringing ecosystem services into economic decision-making: land use in the United Kingdom. Science 341:45-50.

Bennett, E. M., G. D. Peterson, and L. J. Gordon. 2009. Understanding relationships among multiple ecosystem services. Ecology Letters 12:1-11.

Bommarco, R., D. Kleijn, and S. G. Potts. 2012. Insect pollination enhances seed yield, quality, and market value in oilseed rape. Oecologia 169:1025-1032.

Braat, L., and P. ten Brink, editors. 2008. The Cost of Policy Inaction (COPI): The case of not meeting the 2010 biodiversity target. Alterra Wageningen University and Research; Institute for European Environmental Policy (IIEP); Ecologic; Fondazione Eni Enrico Mattei (FEEM); GHK; Milieu en Natuurplanbureau; United Nations Environmental Programme-World Conservation Monitoring Centre; Witteveen en Bos, Wageningen, Netherlands. 
Breeze, T. D., B. E. Vaissière, R. Bommarco, T. Petanidou, N. Seraphides, L. Kozák, J. Scheper, J. C. Biesmeijer, D. Kleijn, and S. Gyldenkærne. 2014. Agricultural policies exacerbate honeybee pollination service supply-demand mismatches across Europe. PLoS ONE 9:e82996.

Bretagnolle, V., and S. Gaba. 2015. Weeds for bees? A review. Agronomy for Sustainable Development 35:891-909.

Brosi, B. J., P. R. Armsworth, and G. C. Daily. 2008. Optimal design of agricultural landscapes for pollination services. Conservation Letters 1:27-36.

Cardinale, B. J., et al. 2012. Biodiversity loss and its impact on humanity. Nature 486:59-67.

Clough, Y., et al. 2011. Combining high biodiversity with high yields in tropical agroforests. Proceeding of the National Academy of Sciences USA 108:8311-8316.

Craven, D., et al. 2016. Plant diversity effects on grassland productivity are robust to both nutrient enrichment and drought. Proceedings of the Royal Society B 283:20150277.

Crawley, M. J., and J. E. Harral. 2001. Scale dependence in plant biodiversity. Science 291:864-868.

Deguines, N., C. Jono, M. Baude, M. Henry, R. Julliard, and C. Fontaine. 2014. Large-scale trade-off between agricultural intensification and crop pollination services. Frontiers in Ecology and the Environment 12:212-217.

Duflot, R., S. Aviron, A. Ernoult, L. Fahrig, and F. Burel. 2015. Reconsidering the role of 'semi-natural habitat' in agricultural landscape biodiversity: a case study. Ecological Research 30:75-83.

Encinas-Viso, F., T. A. Revilla, and R. S. Etienne. 2014. Shifts in pollinator population structure may jeopardize pollination service. Journal of Theoretical Biology 352:24-30.

FAO. 2009. The state of food insecurity in the world: economic crises-impacts and lessons learned. FAO, Rome, Italy.

FAO. 2011. FAOSTAT statistical database. http://faostat.fao.org/

Gaba, S., E. Gabriel, J. Chadœuf, F. Bonneu, and V. Bretagnolle. 2016. Herbicides do not ensure for higher wheat yield, but eliminate rare plant species. Scientific Reports 6:30112.

Gagic, V., S. Hänke, C. Thies, C. Scherber, Ž. Tomanović, and T. Tscharntke. 2012. Agricultural intensification and cereal aphid-parasitoid-hyperparasitoid food webs: network complexity, temporal variability and parasitism rates. Oecologia 170:1099-1109.

Garibaldi, L. A., M. A. Aizen, A. M. Klein, S. A. Cunningham, and L. D. Harder. 2011 $a$. Global growth and stability of agricultural yield decrease with pollinator dependence. Proceeding of the National Academy of Sciences USA 108:59095914.

Garibaldi, L. A., et al. 2011b. Stability of pollination services decreases with isolation from natural areas despite honey bee visits. Ecology Letters 14:1062-1072.

Garibaldi, L. A., et al. 2013. Wild pollinators enhance fruit set of crops regardless of honey bee abundance. Science 339:1608-1611.

Garibaldi, L. A., et al. 2014. From research to action: enhancing crop yield through wild pollinators. Frontiers in Ecology and the Environment 12:439-447.

Geib, J. C., J. P. Strange, and C. Galenj. 2015. Bumble bee nest abundance, foraging distance, and host-plant reproduction: implications for management and conservation. Ecological Applications 25:768-778.

Ghazoul, J., and L. P. Koh. 2010. Food security not (yet) threatened by declining pollination. Frontiers in Ecology and the Environment 8:9-10.

Gils, S., W. H. van der Putten, and D. Kleijn. 2016. Can aboveground ecosystem services compensate for reduced fertilizer input and soil organic matter in annual crops? Journal of Applied Ecology 53:1186-1194.
Godfray, H.-J., J. R. Beddington, I. R. Crute, L. Haddad, D. Lawrence, J. F. Muir, J. Pretty, S. Robinson, S. M. Thomas, and C. Toulmin. 2010. Food security: the challenge of feeding 9 billion people. Science 327:812-818.

Goulson, D., E. Nicholls, C. Botías, and E. L. Rotheray. 2015. Bee declines driven by combined stress from parasites, pesticides, and lack of flowers. Science 347:1255957.

Gounand, I., N. Mouquet, E. Canard, F. Guichard, C. Hauzy, and D. Gravel. 2014. The paradox of enrichment in metaecosystems. American Naturalist 184:752-763.

Green, R. E., S. J. Cornell, J. P. W. Scharlemann, and A. Balmford. 2005. Farming and the fate of wild nature. Science 307:550-555.

Harrison, P. A., et al. 2010. Identifying and prioritizing services in European terrestrial and freshwater ecosystems. Biodiversity Conservation 19:2791-2821.

Heink, U., J. Hauck, K. Jax, and U. Sukopp. 2016. Requirements for the selection of ecosystem service indicators-the case of MAES indicators. Ecological Indicators 61:18-26.

Henckel, L., L. Börger, H. Meiss, S. Gaba, and V. Bretagnolle. 2015. Organic fields sustain weed metacommunity dynamics in farmland landscapes. Proceedings of the Royal Society B 282:20150002.

Holland, J. N. 2015. Population ecology of mutualism. Pages 133-158 in J. Bronstein, editor. Mutualism. Oxford University Press, Oxford, UK.

Holland, J. N., and D. L. DeAngelis. 2010. A consumer-resource approach to the density-dependent population dynamics of mutualism. Ecology 91:1286-1295.

Holland, J. N., Y. Wang, S. Shan, and D. L. DeAngelis. 2013. Consumer-resource dynamics of indirect interactions in a mutualism-parasitism food web module. Theoretical Ecology 6:475-493.

Holzschuh, A., et al. 2016. Mass-flowering crops dilute pollinator abundance in agricultural landscapes across Europe. Ecology Letters 19:1228-1236.

Keitt, T. H. 2009. Habitat conversion, extinction thresholds and pollination services in agroecosystems. Ecological Applications 19:1561-1573.

Kennedy, C. M., et al. 2013. A global quantitative synthesis of local and landscape effects on wild bee pollinators in agroecosystems. Ecology Letters 16:584-599.

Kleijn, D., et al. 2015. Delivery of crop pollination services is an insufficient argument for wild pollinator conservation. Nature Communications 6:7414.

Klein, A.-M., B. E. Vaissière, J. H. Cane, I. Steffan-Dewenter, S. A. Cunningham, C. Kremen, and T. Tscharntke. 2007. Importance of pollinators in changing landscapes for world crops. Proceedings of the Royal Society B 274:303-313.

Kremen, C., N. M. Williams, R. L. Bugg, J. P. Fay, and R. W. Thorp. 2004. The area requirements of an ecosystem service: crop pollination by native bee communities in California. Ecology Letters 7:1109-1119.

Lande, R., S. Engen, and B.-E. Saether. 2003. Stochastic population dynamics in ecology and conservation. Oxford University Press, Oxford, UK.

Lechenet, M., F. Dessaint, G. Py, D. Makowski, and N. Munier-Jolain. 2017. Reducing pesticide use while preserving crop productivity and profitability on arable farms. Nature Plants 3:17008.

Leroux, S. J., and M. Loreau. 2008. Subsidy hypothesis and strength of trophic cascades across ecosystems. Ecology Letters 11:1147-1156.

Lindström, S. A. M., L. Herbertsson, M. Rundölf, R. Bommarco, and H. G. Smith. 2016. Experimental evidence that honeybees depress wild insect densities in a flowering crop. Proceedings of the Royal Society B 283:20161641. 
Loreau, M., and C. de Mazancourt. 2013. Biodiversity and ecosystem stability: a synthesis of underlying mechanisms. Ecology Letters 16:106-115.

Mace, G. M., K. Norris, and A. H. Fitter. 2012. Biodiversity and ecosystem services: a multi-layered relationship. Trend in Ecology \& Evolution 27:19-26.

Macfadyen, S., P. G. Craze, A. Polaszek, K. van Achterberg, and J. Memmott. 2011. Parasitoid diversity reduces the variability in pest control services across time on farms. Proceedings of the Royal Society B 278:3387-3394.

Macfadyen, S., and W. Muller. 2013. Edges in agricultural landscapes: species interactions and movement of natural enemies. PLOS ONE 8:e59659.

McCann, K. S., J. B. Rasmussen, and J. Umbanhowar. 2005. The dynamics of spatially coupled food webs. Ecology Letters 8:513-523.

Mitchell, M. G. E., E. M. Bennett, and A. Gonzalez. 2015. Strong and non-linear effects of fragmentation on ecosystem service provision at multiple scales. Environmental Research Letters 10:094014.

Morales, M. A. 2011. Model selection analysis of temporal variation in benefit for an ant-tended treehopper. Ecology 92:709-719.

Nelson, E., et al. 2009. Modeling multiple ecosystem services, biodiversity conservation, commodity production, and tradeoffs at landscape scales. Frontiers in Ecology and the Environment 7:4-11.

Öckinger, E., and H. G. Smith. 2007. Semi-natural grasslands as population sources for pollinating insects in agricultural landscapes. Journal of Applied Ecology 44:50-59.

Pywell, R. F., M. S. Heard, B. A. Woodcock, S. Hinsley, L. Ridding, M. Nowakowski, and J. M. Bullock. 2015. Wildlifefriendly farming increases crop yield: evidence for ecological intensification. Proceedings of the Royal Society B 282:20151740.

R Core Team. 2016. R: a language and environment for statistical computing. R Foundation for Statistical Computing, Vienna, Austria. www.r-project.org

Ray, D. K., N. Ramankutty, N. D. Mueller, P. C. West, and J. A. Foley. 2012. Recent patterns of crop yield growth and stagnation. Nature Communications 3:1293.
Rollin, O., V. Bretagnolle, A. Decourtye, J. Aptel, N. Michel, B. E. Vaissiere, and M. Henry. 2013. Differences of floral resource use between honeybees and wild bees in an intensive farming system. Agriculture, Ecosystems and Environment 179:78-86.

Roubik, D. W. 2015. Pollination of cultivated plants in the tropics. Agricultural Services Bulletin 118. Food and Agriculture Organization, Rome, Italy.

Schmidhuber, J., and F. N. Tubiello. 2007. Global food security under climate change. Proceedings of the National Academy of Sciences USA 104:19703-19708.

Serna-Chavez, H. M., C. J. E. Schulp, P. M. van Bodegom, W. Bouten, P. H. Verburg, and M. D. Davidson. 2014. A quantitative framework for assessing spatial flows of ecosystem services. Ecological Indicators 39:24-33.

Sutter, L., and M. Albrecht. 2016. Synergistic interactions of ecosystem services: florivorous pest control boosts crop yield increase through insect pollination. Proceedings of the Royal Society B 283:20152529.

Tamburini, G., S. De Simone, M. Sigura, F. Boscutti, and L. Marini. 2016. Soil management shapes ecosystem service provision and trade-offs in agricultural landscapes. Proceedings of the Royal Society B 283:20161369.

Thebault, E., and C. Fontaine. 2010. Stability of ecological communities and the architecture of mutualistic and trophic networks. Science 329:853-856.

Thompson, A. R., R. M. Nisbet, and R. J. Schmitt. 2006. Dynamics of mutualist populations that are demographically open. Journal of Animal Ecology 75:1239-1251.

Tilman, D., P. B. Reich, and J. M. H. Knops. 2006. Biodiversity and ecosystem stability in a decade-long grassland experiment. Nature 441:629-632.

Tscharntke, T., et al. 2012. Landscape moderation of biodiversity patterns and processes-eight hypotheses. Biological Reviews 87:661-685.

Williams, I. H. 1994. The dependence of crop production within the European Union on pollination by honey bees. Agricultural Zoology Reviews 6:229-257.

Zurbuchen, A., L. Landert, J. Klaiber, A. Müller, S. Hein, and S. Dorn. 2010. Maximum foraging ranges in solitary bees: only few individuals have the capability to cover long foraging distances. Biological Conservation 143:669-676.

\section{SUPPORTING INFORMATION}

Additional supporting information may be found online at: http://onlinelibrary.wiley.com/doi/10.1002/eap.1853/full

Data Availability

Data are available from the Dryad Digital Repository: https://doi.org/10.5061/dryad.533qk3d 